Research Article

\title{
Determination of the Binding Parameters between Proteins and Luminol by Chemiluminescence Using Flow Injection Technique
}

\author{
Jie Guo, Donghua Chen, and Zhenghua Song \\ Key Laboratory of Synthetic and Natural Functional Molecule Chemistry of Ministry of Education, \\ College of Chemistry \& Material Science, Northwest University, Xian 710069, China \\ Correspondence should be addressed to Zhenghua Song; songzhenghua@hotmail.com
}

Received 8 April 2013; Accepted 16 May 2013

Academic Editors: Z. Arslan and K. Ohyama

Copyright (C) 2013 Jie Guo et al. This is an open access article distributed under the Creative Commons Attribution License, which permits unrestricted use, distribution, and reproduction in any medium, provided the original work is properly cited.

\begin{abstract}
The interaction behavior of bovine serum albumin (BSA), lysozyme (LYS), myoglobin (MB), and catalase (CAT) with luminol, respectively, was first studied by chemiluminescence $(\mathrm{CL})$ using flow injection (FI) technique based on the fact that the studied proteins can enhance the CL intensity of luminol. A FI-CL model of protein-luminol interaction, $\lg \left[\left(I_{0}-I\right) / I\right]=1 / n \lg [P]+1 / n \lg K_{a}+$ $2 \lg n$, was constructed, and the interaction parameters of BSA, LYS, MB, and CAT with luminol were determined accordingly. The binding constants $K_{a}$ are in the descending order of CAT $>\mathrm{MB}>\mathrm{LYS}>\mathrm{BSA}$ at the level of $10^{5}$ to $10^{7} \mathrm{~L} \mathrm{~mol}^{-1}$, and the number of binding sites $n$ of luminol to BSA or LYS is around 2 and to MB or CAT is around 1 . The results of thermodynamic parameters $(\triangle H$, $\Delta S$, and $\Delta G$ ) showed that the binding processes of luminol to the four proteins are spontaneous mainly through the hydrophobic force.
\end{abstract}

\section{Introduction}

Proteins possess many biological functions including binding, catalysis, operating as molecular switches, and serving as structural components of cells and organisms $[1,2]$ and play an important role in the transportation and deposition of various endogenous and exogenous substances [3, 4]. In recent years, the interaction of protein with small molecules has become a hot spot in the fields of chemistry, biology, and medicine [5-7]. As common model proteins, bovine serum albumin (BSA) [8], lysozyme (LYS) [9], myoglobin (MB) [10], and catalase (CAT) [11] are widely applied to the study of protein-small molecule interaction. Accordingly, many methods have been utilized to investigate this hot topic, such as fluorescence spectroscopy [12], resonance light scattering [13], circular dichroism [14], nuclear magnetic resonance spectroscopy [15], and chemiluminescence (CL) with flow injection (FI) technique [16]. The FI-CL analysis has proven to be a very useful analytical method with advantages of simple apparatus, high sensitivity, wide dynamic ranges, reproducibility, automatability, less reagent consumption [17$19]$, and so forth.

Luminol (5-amino-2, 3-dihydro-1, 4-phthalazinedione) is known to produce $\mathrm{CL}$ with the characteristic wavelength of $425 \mathrm{~nm}$ under alkaline condition [20,21], making it widely used around the world as a blood enhancement technique in forensic science. Also this luminescent compound is used clinically in the treatment of alopecia [22], the promotion of blood clotting [23], and wound healing [24]. Due to its high quantum yield, the CL of luminol has been used in many laboratory applications, including environmental field of analyzing trace metals [25, 26], food safety field [27], biological field of immunoassays, monitoring of metabolic pathways, and detection of free radicals [28]. Recently, the $\mathrm{CL}$ of luminol has been employed to study its interaction behavior with serum albumins [12, 29].

In our previous study, it was found that BSA, LYS, MB, and CAT can accelerate the electrons transferring rate of excited 3-aminophthalate leading to enhancement of CL intensity from luminol [30-33]. However, no comprehensive 
data have been available on the binding parameters of the four proteins with luminol so far. The main aims of the current paper are to: (a) construct a mathematical model of proteinluminol interaction: $\lg \left[\left(I_{0}-I\right) / I\right]=1 / n \lg [P]+1 / n \lg K_{a}+$ $2 \lg n$, based on the enhancing effect of protein-to-luminol CL intensity, (b) obtain the binding parameters of proteins with luminol, and (c) give the thermodynamic parameters of protein-luminol binding process.

\section{Materials and Methods}

2.1. Reagents. All reagents used were of analytical reagent grade unless otherwise specified and doubly deionized water was purified in a Milli-Q system (Millipore, Bedford, MA, USA) for the preparation of solutions in the whole procedure. Luminol (Fluka, Switzerland), BSA (Sigma), LYS (Sigma), MB (Sigma), and CAT (Sigma) were used as received without further purification. Luminol $\left(2.5 \times 10^{-2} \mathrm{~mol} \mathrm{~L}^{-1}\right)$ was prepared by dissolving $0.44 \mathrm{~g}$ luminol in $100 \mathrm{~mL}$ of $0.1 \mathrm{~mol} \mathrm{~L}^{-1}$ $\mathrm{NaOH}$ solution in a brown calibrated flask. BSA, LYS, MB, and CAT $\left(5.0 \times 10^{-5} \mathrm{~mol} \mathrm{~L}^{-1}\right)$ were prepared in purified water and stored at $4^{\circ} \mathrm{C}$.

2.2. Apparatus. The FI-CL system used in this work was illustrated schematically in Figure 1. The flow system consisted of three lines for delivery protein, luminol $/ \mathrm{NaOH}$, and carrier solution. The IFFM-A Luminescence Analyzer (Xi'an Remax Electronic Science and Technology Co., and Ltd., Xian, China) contained the sampling system, the photomultiplier tube (PMT), and the PC with an IFFM-A client system (Remax, Xi'an, China). Polytetrafluoroethylene (PTFE) tube $(1.0 \mathrm{~mm}$ i.d.) was used to connect all the components of the flow system. A six-way valve with a loop of $100 \mu \mathrm{L}$ was used for quantitatively injecting luminol into carrier stream. The CL detector contained a flow cell made by coiling $15 \mathrm{~cm}$ of colorless glass tube $(1.0 \mathrm{~mm}$ i.d.) into a spiral disk shape with a diameter of $2.0 \mathrm{~cm}$ and placed close to the PMT. Extreme precautions were taken to ensure that the sample compartment and PMT were light tight. The CL signal produced in flow cell was detected without wavelength discrimination, and the PMT output was recorded by computer with IFFM-E client system. The temperature of the solutions was controlled $\left(T \pm 0.1^{\circ} \mathrm{C}\right)$ in a water bath.

2.3. General Procedures. The carrier (purified water), the solutions of luminol, and proteins were propelled by peristaltic pumps at a flow rate of $2.0 \mathrm{~mL} \mathrm{~min}$ on each flow line. The whole flow system was washed until a stable baseline was recorded. Then $100 \mu \mathrm{L}$ of luminol solution was injected into the carrier stream by the six-way valve and merged with proteins. The whole mixed solution was delivered into the flow cell, and the emitted CL was collected by the PMT at a voltage of $-700 \mathrm{~V}$ and recorded by the computer. The increment of CL intensity $\left(\Delta I=I-I_{0}\right.$, where $I$ and $I_{0}$ were CL signals in the presence and in the absence of proteins) was measured.

2.4. Optimization of the Experimental Conditions. The effect of luminol concentration on the CL intensity was examined

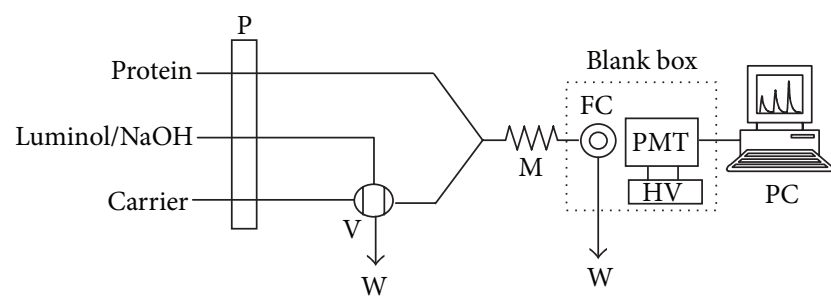

FIgURE 1: Schematic diagram of the present FI-CL system. P: pump; M: mixing tube; V: valve; FC: flow cell; W: waste; PC: personal computer.

over the ranges of $5.0 \times 10^{-7}$ to $5.0 \times 10^{-4} \mathrm{~mol} \mathrm{~L}^{-1}$. It was found that the maximum CL intensity could be obtained at $2.5 \times 10^{-5} \mathrm{~mol} \mathrm{~L}^{-1}$ luminol. Therefore, $2.5 \times 10^{-5} \mathrm{~mol} \mathrm{~L}^{-1}$ luminol was chosen as the optimum concentration and used in subsequent experiments. A series of $\mathrm{NaOH}$ solutions with different concentrations ranging from $1.0 \times 10^{-3}$ to $0.1 \mathrm{~mol} \mathrm{~L}^{-1}$ were tested, and $2.5 \times 10^{-2} \mathrm{~mol} \mathrm{~L}^{-1} \mathrm{NaOH}$ was used as the optimum concentration. The flow rate and the length of mixing tube had a great effect on the CL intensity. A flow rate of $2.0 \mathrm{~mL} \mathrm{~min}^{-1}$ and the length of mixing tube of $10.0 \mathrm{~cm}$ were selected in this work with good sensitivity, precision, and reproducibility.

2.5. The Operational Stability of the FI-CL System. Luminol alkaline solution $(100 \mu \mathrm{L})$ was injected into the flow system in the presence of $2.5 \times 10^{-5} \mathrm{~mol} \mathrm{~L}^{-1}$ luminol and $5.0 \times$ $10^{-8} \mathrm{~mol} \mathrm{~L}^{-1}$ proteins, and the CL intensity was recorded to test the stability of luminol-protein system. This experiment lasted for 3 days, and the flow system was regularly used over 8 hours per day. The results showed that the relative standard deviations were less than $3.0 \%$, so the luminol-protein system exerted good stability.

2.6. Constructing the Binding Model of Protein with Luminol. It is known that proteins are biomacromolecules with binding sites for small molecules. Assuming that the number of binding sites of the small molecule luminol $(L)$ to protein $(P)$ is $n$, each site is independent and has the same intrinsic affinity for the ligand $[34,35]$. The protein-luminol complex $\left(P L_{n}\right)$ is formed, and the binding process can be expressed as follows:

$$
P+n L \stackrel{K_{a}}{\rightleftharpoons} P L_{n}
$$

or

$$
\frac{1}{n} P+L \stackrel{K}{\rightleftharpoons} P_{1 / n} L,
$$

where $P, L, n$, and $P L_{n}$ represent protein, luminol, the number of binding sites, and protein-luminol complex, respectively. The binding constant $K_{a}$ or $K$ is

$$
K_{a}=\frac{\left[P L_{n}\right]}{[P][L]^{n}} \quad \text { or } \quad K=\frac{\left[P_{1 / n} L\right]}{[P]^{1 / n}[L]},
$$

where $\left[P L_{n}\right],[P]$, and $[L]$ represent the concentrations of protein-luminol complex, protein, and luminol at equilibrium state, respectively, and $\left[P_{1 / n} L\right]$ is the concentration of product for reaction (2). 
According to chemical reaction equilibrium theory,

$$
\begin{gathered}
K_{a}=K^{n}, \\
{\left[P_{1 / n} L\right]=\frac{1}{n}[P]_{b}=\frac{1}{n^{2}}[L]_{b} .}
\end{gathered}
$$

The CL intensity of luminol is proportional to its concentration. Equations (6) and (7) can be obtained as

$$
I_{0} \propto[L]_{t}
$$

where $I_{0}$ is the CL intensity in the absence of protein; $[L]_{t}$ is the total concentration of luminol as

$$
I-I_{0} \propto[L]_{b},
$$

where $I$ is the CL intensity in the presence of protein; $[L]_{b}$ is the concentration of luminol at equilibrium. Using (6) and (7) in (5) leads to

$$
K=\frac{\left(1 / n^{2}\right)\left(I-I_{0}\right)}{[P]^{1 / n} I_{0}} .
$$

Taking logarithms of both sides,

$$
\lg \frac{I-I_{0}}{I_{0}}=\frac{1}{n} \lg [P]+\lg K+2 \lg n .
$$

Substituting (4) into (9), the following equation can be obtained:

$$
\lg \frac{I-I_{0}}{I_{0}}=\frac{1}{n} \lg [P]+\frac{1}{n} \lg K_{a}+2 \lg n .
$$

Equation (10) is the FI-CL model for determination of binding parameters of protein with luminol from intercept and slope of $\lg \left(I_{0}-I\right) / I \sim \lg [P]$ curve.

\section{Results and Discussion}

3.1. Relative CL Intensity-Time Profiles. The relative CL intensity-time profiles in different CL systems were presented in Figure 2. Herein, the concentration of luminol was $2.5 \times$ $10^{-5} \mathrm{~mol} \mathrm{~L}^{-1}$, and the concentrations of BSA, LYS, MB, and CAT were $5.0 \times 10^{-8} \mathrm{~mol} \mathrm{~L}^{-1}$. It can be seen that the maximum CL intensity $\left(I_{\max }\right)$ of luminol system (curve 1$)$ is 93 at the time ( $\left.T_{\max }\right)$ of $3.9 \mathrm{~s}$; the $I_{\max }$ is $144,152,221$, and 410 at the $T_{\max }$ of 3.7,3.4, 3.2, and $2.9 \mathrm{~s}$ in the presence of BSA (curve 2), LYS (curve 3), MB (curve 4), and CAT (curve 5), respectively. It can be seen that the CL responses for different proteins in luminol system followed the order of CAT $>$ MB $>$ LYS $>$ BSA.

3.2. Binding Parameters of Protein with Luminol. Under the optimum conditions, a series of standard solutions of protein were analyzed by the FI-CL system. The CL intensity increment from luminol obeys the general equation of $\Delta I=A C_{p}+$ $B$, with the linear equations, linear ranges, and correlative coefficients $R$ at different temperatures $(288,298$, and $308 \mathrm{~K})$ listed in Table 1. It can be seen that $A$ varies in the increasing order of $A_{\mathrm{CAT}}>A_{\mathrm{MB}}>A_{\mathrm{LYS}}>A_{\mathrm{BSA}}$, indicating that the

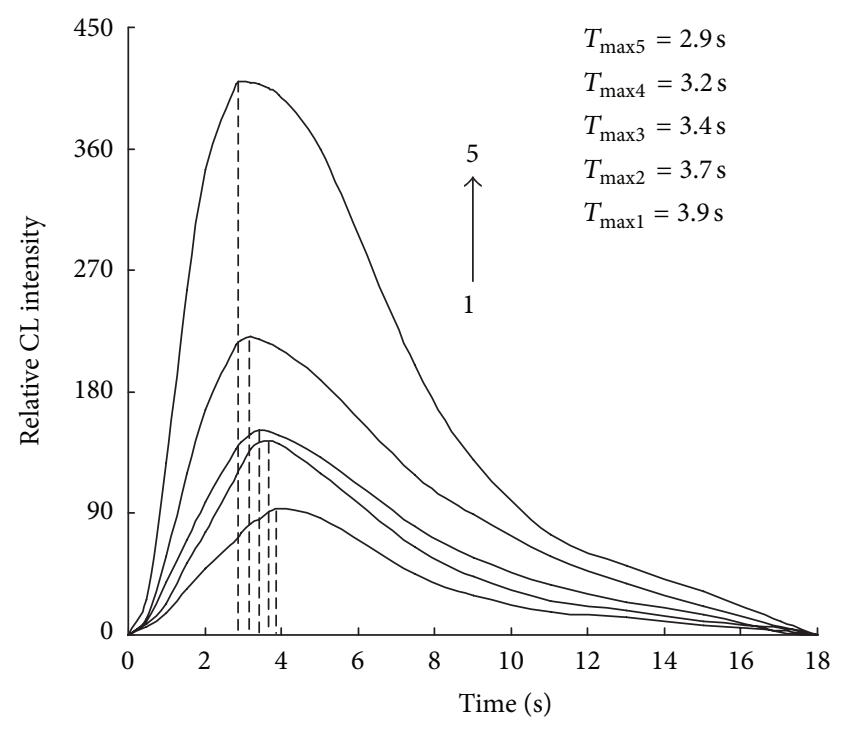

FIGURE 2: Relative CL intensity-time profile in different CL systems at $298 \mathrm{~K}$. Curve 1: luminol CL system; Curve 2: luminol-BSA CL system; Curve 3: luminol-LYS CL system; Curve 4: luminol-MB CL system; Curve 5: luminol-CAT CL system. Concentration: luminol, $2.5 \times 10^{-5} \mathrm{~mol} \mathrm{~L}^{-1}$; BSA, LYS, MB, and CAT, $5.0 \times 10^{-8} \mathrm{~mol} \mathrm{~L}^{-1}$.

sensitivities of determination follow the sequence CAT $>$ $\mathrm{MB}>\mathrm{LYS}>\mathrm{BSA}$. According to (10), $\lg \left[\left(I_{0}-I\right) / I\right]=1 / n \lg [P]+$ $1 / n \lg K_{a}+2 \lg n$, by plotting $\lg \left(I_{0}-I\right) / I$ versus $\lg [P]$, the binding constants $K_{a}$ and the number of binding sites $n$ of luminol to CAT, MB, LYS, and BSA were obtained and were given in Table 1. It was clear that the binding constants $K_{a}$ increase with the increasing of temperature, and the values of $K_{a}$ were at $10^{5}$ to $10^{7}$ levels suggesting that there existed a high binding affinity of proteins with luminol in the sequence of CAT $>M B$ $>$ LYS $>$ BSA. The number of binding sites $n$ of luminol to BSA or LYS was about 2 and to MB or CAT was about 1.

3.3. The Thermodynamic Parameters of Protein-Luminol Interaction. By the Van't Hoff equation [36], thermodynamic parameters of BSA, LYS, MB, and CAT with luminol were listed in Table 2. It can be seen that $\Delta H>0, \Delta S>0$, and $\Delta G<$ 0 , indicating that the complex formation was a spontaneous and endothermic process with hydrophobic effect as the main binding force. It was also clear that the major contribution for the $\Delta G$ comes from $\Delta S$ rather than $\Delta H$, suggesting the binding process was entropy-driven. The sequence of binding abilities of different proteins was consistent with the order of the sensitivity of determination: CAT $>$ MB $>$ LYS $>$ BSA, which indicated that the binding of CAT with luminol was much easier than MB, LYS, and BSA.

\section{Conclusions}

The interaction behavior of BSA, LYS, MB, and CAT with luminol was first studied by FI-CL analysis. By the constructed FI-CL model $\lg \left[\left(I_{0}-I\right) / I\right]=1 / n \lg [P]+1 / n \lg K_{a}+$ $2 \lg n$, binding constants $K_{a}$ and the number of binding sites $n$ of protein with luminol were obtained. The results showed that the interaction of protein with luminol was 
TABLE 1: The linear equations and binding parameters by (10).

\begin{tabular}{|c|c|c|c|c|c|}
\hline \multirow{2}{*}{ Protein } & \multirow{2}{*}{$T(\mathrm{~K})$} & \multirow{2}{*}{$\begin{array}{l}\text { Linear equation } / R \\
\Delta I=A C_{p}+B^{\mathrm{a}}\end{array}$} & \multirow{2}{*}{ Linear range $\left(\mathrm{nmol} \mathrm{L}^{-1}\right)$} & \multicolumn{2}{|c|}{$\lg \left(I_{0}-I\right) / I$ versus $\operatorname{Lg}[P]$} \\
\hline & & & & $K_{a}\left(\mathrm{~L} \mathrm{~mol}^{-1}\right)$ & $n$ \\
\hline \multirow{3}{*}{ BSA } & 288 & $\Delta I=0.18 C_{\mathrm{BSA}}+29.91 / 0.9977$ & \multirow{3}{*}{$5-250$} & $1.77 \times 10^{5}$ & 2.23 \\
\hline & 298 & $\Delta I=0.19 C_{\mathrm{BSA}}+32.41 / 0.9963$ & & $2.34 \times 10^{5}$ & 1.75 \\
\hline & 308 & $\Delta I=0.21 C_{\mathrm{BSA}}+35.57 / 0.9978$ & & $2.90 \times 10^{5}$ & 1.80 \\
\hline \multirow{3}{*}{ LYS } & 288 & $\Delta I=0.15 C_{\mathrm{LYS}}+21.49 / 0.9990$ & \multirow{3}{*}{$10-500$} & $1.93 \times 10^{5}$ & 1.95 \\
\hline & 298 & $\Delta I=0.21 C_{\mathrm{LYS}}+21.43 / 0.9961$ & & $4.26 \times 10^{5}$ & 1.75 \\
\hline & 308 & $\Delta I=0.48 C_{\mathrm{LYS}}+22.02 / 0.9988$ & & $5.59 \times 10^{5}$ & 1.96 \\
\hline \multirow{3}{*}{ MB } & 288 & $\Delta I=0.19 C_{\mathrm{MB}}+32.61 / 0.9963$ & \multirow{3}{*}{$10-1000$} & $2.12 \times 10^{6}$ & 1.26 \\
\hline & 298 & $\Delta I=0.21 C_{\mathrm{MB}}+58.55 / 0.9966$ & & $2.40 \times 10^{6}$ & 1.35 \\
\hline & 308 & $\Delta I=0.29 C_{\mathrm{MB}}+49.22 / 0.9961$ & & $2.93 \times 10^{6}$ & 0.94 \\
\hline \multirow{3}{*}{ CAT } & 288 & $\Delta I=4.91 C_{\mathrm{CAT}}+14.85 / 0.9962$ & \multirow{3}{*}{$0.1-100$} & $4.38 \times 10^{7}$ & 1.38 \\
\hline & 298 & $\Delta I=5.58 C_{\mathrm{CAT}}+15.74 / 0.9997$ & & $4.96 \times 10^{7}$ & 1.36 \\
\hline & 308 & $\Delta I=6.14 C_{\mathrm{CAT}}+13.30 / 0.9996$ & & $5.93 \times 10^{7}$ & 1.24 \\
\hline
\end{tabular}

${ }^{\mathrm{a}}$ Each result is the average of seven separate determinations.

TABLE 2: Thermodynamic parameters of protein-luminol interaction determined by FI-CL.

\begin{tabular}{|c|c|c|c|c|}
\hline Protein & $T(\mathrm{~K})$ & $\Delta G\left(\mathrm{~kJ} \mathrm{~mol}^{-1}\right)$ & $\Delta H\left(\mathrm{~kJ} \mathrm{~mol}^{-1}\right)$ & $\Delta S\left(\mathrm{~J} \mathrm{~mol}^{-1} \mathrm{~K}^{-1}\right)$ \\
\hline \multirow{3}{*}{ BSA } & 288 & -28.94 & \multirow{3}{*}{18.10} & \multirow{3}{*}{163.37} \\
\hline & 298 & -30.63 & & \\
\hline & 308 & -32.20 & & \\
\hline \multirow{3}{*}{ LYS } & 288 & -29.14 & \multirow{3}{*}{40.68} & \multirow{3}{*}{243.03} \\
\hline & 298 & -32.11 & & \\
\hline & 308 & -33.98 & & \\
\hline \multirow{3}{*}{ MB } & 288 & -34.87 & \multirow{3}{*}{12.00} & \multirow{3}{*}{162.62} \\
\hline & 298 & -36.40 & & \\
\hline & 308 & -38.13 & & \\
\hline \multirow{3}{*}{ CAT } & 288 & -42.13 & \multirow{3}{*}{11.19} & \multirow{3}{*}{185.07} \\
\hline & 298 & -43.90 & & \\
\hline & 308 & -45.83 & & \\
\hline
\end{tabular}

an endothermic, spontaneous, and entropy-driven process mainly via the hydrophobic effect.

\section{Conflict of Interests}

The authors and commercial identities in this work do not have any possible conflict of interests.

\section{Acknowledgments}

The authors gratefully acknowledge the financial support from the National Nature Science Foundation of China (no. 21275118), the NWU Graduate Innovation and Creativity Fund (no. 10YZZ29), and the Open Funds from the Key Laboratory of Synthetic and Natural Functional Molecule Chemistry of Ministry of Education, China.

\section{References}

[1] K. Teilum, J. G. Olsen, and B. B. Kragelund, "Functional aspects of protein flexibility," Cellular and Molecular Life Sciences, vol. 66, no. 14, pp. 2231-2247, 2009.
[2] A. Dhar, K. Girdhar, D. Singh, H. Gelman, S. Ebbinghaus, and M. Gruebele, "Protein stability and folding kinetics in the nucleus and endoplasmic reticulum of Eucaryotic Cells," Biophysical Journal, vol. 101, no. 2, pp. 421-430, 2011.

[3] G. Paramaguru, A. Kathiravan, S. Selvaraj, P. Venuvanalingam, and R. Renganathan, "Interaction of anthraquinone dyes with lysozyme: evidences from spectroscopic and docking studies," Journal of Hazardous Materials, vol. 175, no. 1-3, pp. 985-991, 2010.

[4] R. J. Pantazes, M. J. Grisewood, and C. D. Maranas, "Recent advances in computational protein design," Current Opinion in Structural Biology, vol. 21, no. 4, pp. 467-472, 2011.

[5] H. M. Zhang, J. Chen, Q. H. Zhou, Y. Q. Shi, and Y. Q. Wang, "Study on the interaction between cinnamic acid and lysozyme," Journal of Molecular Structure, vol. 987, no. 1-3, pp. 7-12, 2011.

[6] N. Shahabadi and M. Mohammadpour, "Study on the interaction of sodium morin-5-sulfonate with bovine serum albumin by spectroscopic techniques," Spectrochimica Acta A, vol. 86, pp. 191-195, 2012.

[7] W. Du, T. Teng, C. C. Zhou, L. Xi, and J. Z. Wang, "Spectroscopic studies on the interaction of bovine serum albumin with ginkgolic acid: binding characteristics and structural analysis," Journal of Luminescence, vol. 132, no. 5, pp. 1207-1214, 2012.

[8] G. W. Zhang, N. Zhao, X. Hu, and J. Tian, "Interaction of alpinetin with bovine serum albumin: probing of the mechanism and binding site by spectroscopic methods," Spectrochimica Acta A, vol. 76, no. 3-4, pp. 410-417, 2010.

[9] W. P. Wang, W. A. Min, J. R. Chen, X. H. Wu, and Z. D. Hu, "Binding study of diprophylline with lysozyme by spectroscopic methods," Journal of Luminescence, vol. 131, no. 4, pp. 820-824, 2011.

[10] D. Ganini, M. Christoff, M. Ehrenshaft, M. B. Kadiiska, R. P. Mason, and E. J. H. Bechara, "Myoglobin $-\mathrm{H}_{2} \mathrm{O}_{2}$ catalyzes the oxidation of $\beta$-ketoacids to $\alpha$-dicarbonyls: mechanism and implications in ketosis," Free Radical Biology and Medicine, vol. 51, no. 3, pp. 733-743, 2011.

[11] M. I. González-Sánchez, F. García-Carmona, H. Macià, and E. Valero, "Catalase-like activity of human methemoglobin: a kinetic and mechanistic study," Archives of Biochemistry and Biophysics, vol. 516, no. 1, pp. 10-20, 2011. 
[12] N. S. Moyon and S. Mitra, "Luminol fluorescence quenching in biomimicking environments: sequestration of fluorophore in hydrophobic domain," Journal of Physical Chemistry B, vol. 115, no. 33, pp. 10163-10172, 2011.

[13] J. B. Xiao, J. W. Chen, H. Cao, and F. L. Ren, "Study of the interaction between baicalin and bovine serum albumin by multi-spectroscopic method," Journal of Photochemistry and Photobiology A, vol. 191, no. 2-3, pp. 222-227, 2007.

[14] T. Banerjee, S. K. Singh, and N. Kishore, "Binding of naproxen and amitriptyline to bovine serum albumin: biophysical aspects," Journal of Physical Chemistry B, vol. 110, no. 47, pp. 24147-24156, 2006.

[15] B. L. Cao, S. Endsley, and N. H. Andersen, "19F NMR studies of tryptophan/serum albumin binding," Bioorganic and Medicinal Chemistry, vol. 11, no. 1, pp. 69-75, 2003.

[16] Y. M. Huang, Z. Z. Zhang, D. J. Zhang, and J. D. Lv, "Flowinjection analysis chemiluminescence detection combined with microdialysis sampling for studying protein binding of drug," Talanta, vol. 53, no. 4, pp. 835-841, 2001.

[17] S. Kulmala and J. Suomi, "Current status of modern analytical luminescence methods," Analytica Chimica Acta, vol. 500, no. 1-2, pp. 21-69, 2003.

[18] X. Wang, J. M. Lin, M. L. Liu, and X. L. Cheng, "Flow-based luminescence-sensing methods for environmental water analysis," Trends in Analytical Chemistry, vol. 28, no. 1, pp. 75-87, 2009.

[19] M. C. Icardo and J. M. Calatayud, "Photo-induced luminescence," Critical Reviews in Analytical Chemistry, vol. 38, no. 2, pp. 118-130, 2008.

[20] E. H. White, O. Zafiriou, H. H. Kägi, and J. H. M. Hill, "Chemiluminescence of luminol: the chemical reaction," Journal of the American Chemical Society, vol. 86, no. 5, pp. 940-941, 1964.

[21] J. M. Sanders, L. J. Chen, L. T. Burka, and H. B. Matthews, "Metabolism and disposition of luminol in the rat," Xenobiotica, vol. 30 , no. 3 , pp. 263-272, 2000.

[22] S. Irie, "The treatment of alopecia areata with 3-aminophthalhydrazide," Current Therapeutic Research, Clinical and Experimental, vol. 2, no. 3, pp. 107-110, 1960.

[23] S. Irie, "Influence of 3-aminophthalhydrazide on the prothrombin time," Current Therapeutic Research, Clinical and Experimental, vol. 2, no. 5, pp. 153-157, 1960.

[24] S. Irie, "The treatment of wounds with 3-aminophthalhydrazide," The American surgeon, vol. 27, pp. 642-645, 1961.

[25] H. Zhang, T. Shibata, T. Krawczyk et al., "Facile detection of proteins on a solid-phase membrane by direct binding of dextran-based luminol-biotin chemiluminescent polymer," Talanta, vol. 79, no. 3, pp. 700-705, 2009.

[26] S. Bi, H. Zhou, and S. Zhang, "Multilayers enzyme-coated carbon nanotubes as biolabel for ultrasensitive chemiluminescence immunoassay of cancer biomarker," Biosensors and Bioelectronics, vol. 24, no. 10, pp. 2961-2966, 2009.

[27] K. Mervartová, M. Polášek, and J. M. Calatayud, "Recent applications of flow-injection and sequential-injection analysis techniques to chemiluminescence determination of pharmaceuticals," Journal of Pharmaceutical and Biomedical Analysis, vol. 45, no. 3, pp. 367-381, 2007.

[28] A. R. Bowie, M. G. Sanders, and P. J. Worsfold, "Analytical applications of liquid phase chemiluminescence reactions-a review," Journal of Bioluminescence and Chemiluminescence, vol. 11, no. 2, pp. 61-90, 1996.
[29] N. S. Moyon and S. Mitra, "On the interaction of luminol with human serum albumin: nature and thermodynamics of ligand binding," Chemical Physics Letters, vol. 498, no. 1-3, pp. 178-183, 2010.

[30] X. J. Tan, Z. H. Song, D. H. Chen, and Z. M. Wang, "Study on the chemiluminescence behavior of bovine serum albumin with luminol and its analytical application," Spectrochimica Acta A, vol. 79, no. 1, pp. 232-235, 2011.

[31] D. H. Chen and Z. H. Song, "In vitro monitoring of picogram levels of risperidone in human urine via luminollysozyme flow injection chemiluminescence," Microchimica Acta, vol. 171, no. 3-4, pp. 437-440, 2010.

[32] Z. M. Wang, D. H. Chen, X. Gao, and Z. H. Song, "Subpicogram determination of melamine in milk products using a luminolmyoglobin chemiluminescence system," Journal of Agricultural and Food Chemistry, vol. 57, no. 9, pp. 3464-3469, 2009.

[33] D. H. Chen, Z. M. Wang, Y. Zhang, X. Y. Xiong, and Z. H. Song, "Study on the interaction behavior of catalase with cephalosporins by chemiluminescence with flow injection analysis," Analytical Methods, vol. 4, no. 6, pp. 1485-1487, 2012.

[34] G. Scatchard, "The attraction of proteins for small molecules and ions," Annals of the New York Academy of Sciences, vol. 51, pp. 660-672, 1949.

[35] A. A. Spector, J. E. Fletcher, and J. D. Ashbrook, "Analysis of long-chain free fatty acid binding to bovine serum albumin by determination of stepwise equilibrium constants," Biochemistry, vol. 10, no. 17, pp. 3229-3232, 1971.

[36] P. D. Ross and S. Subramanian, "Thermodynamics of protein association reactions: forces contributing to stability, Biochemistry, vol. 20, no. 11, pp. 3096-3102, 1981. 



\section{Carbohydrate} Chemistry

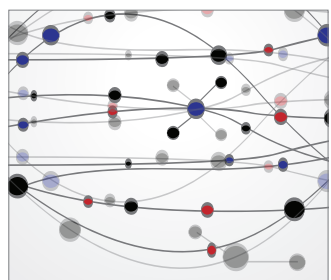

The Scientific World Journal
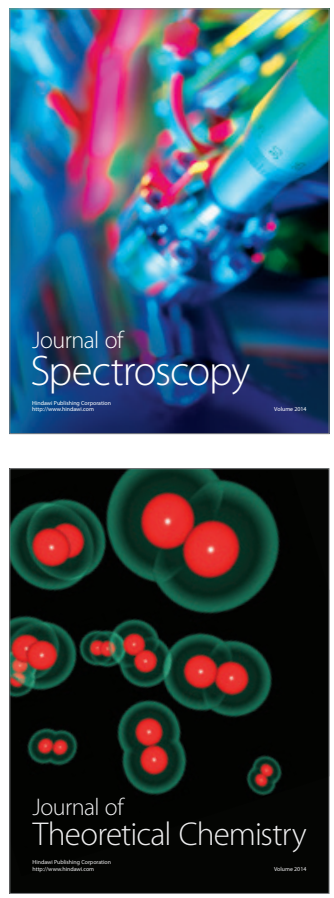


Submit your manuscripts at

http://www.hindawi.com

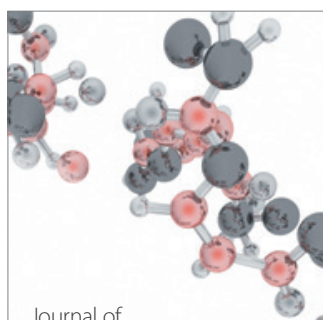

Analytical Methods

in Chemistry

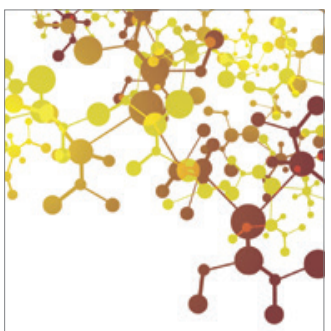

Journal of

Applied Chemistry

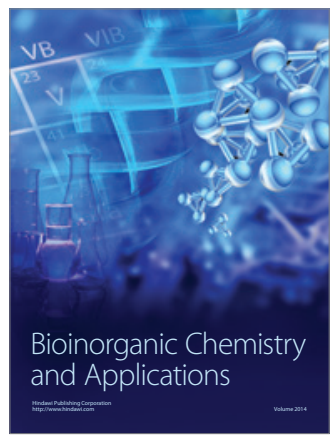

Inorganic Chemistry
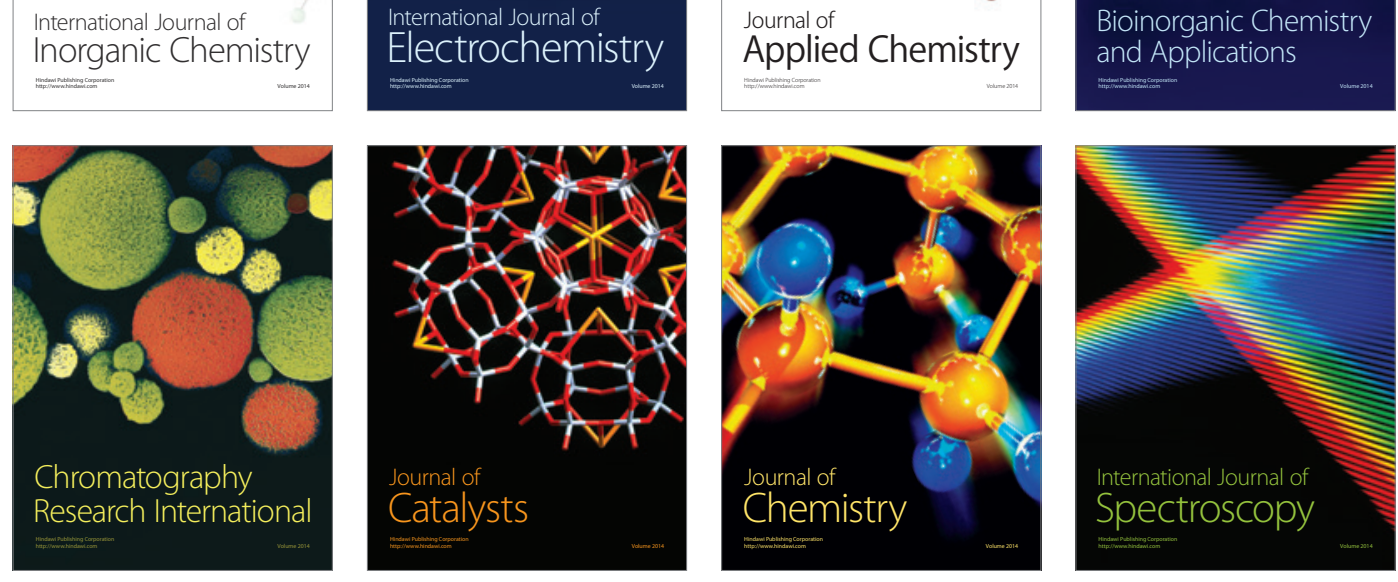